\title{
Direct and indirect effects of TQM on the patients' satisfaction and loyalty in the Jordanian health care
} sector

\author{
Ayman Abu-Rumman ${ }^{a^{*}}$, Anas Mhasnah ${ }^{\mathrm{b}}$ and Tariq Al-Zyout ${ }^{\mathrm{c}}$
}

${ }^{a}$ Associate Professor, Al Ahliyya Amman University, Business School, Jordan

${ }^{b}$ Faculty of Economics and Management Science, University Sultan Zainal Abidin (UINSZA), Malaysia ${ }^{c}$ Royal Medical Service (RMS), Jordan

\section{H R O N I C L E}

\section{Article history:}

Received: June 20, 2020

Received in revised format: August 302020

Accepted: September 15, 2020

Available online:

September 15, 2020

Keywords:

Total Quality Management

Health Care

Service Quality

Patient's Satisfaction

Patient's Loyalty

Private and Public Hospitals

Jordan

\section{Introduction}

The Ministry of Health in Jordan is directly involved in the national health issues where it monitors, organises, and oversees administrative work. The health sector in Jordan is divided into military, public, and private, with all offering a total of 12,557 beds in 2017. In 2018, a total of 13 military hospitals (2,320 beds), 65 public hospitals (3,855 beds) and 45 private hospitals (6,382 beds) were in operation (Ministry of Health, 2018). Statistically, out of the 5 million people in Jordan, $82 \%$ live in cities where $38 \%$ reside within the capital Amman and of which only $73 \%$ were covered by health insurance. Jordan is an expensive country, especially for international patients while the citizens are provided with affordable healthcare services as a part of an agreement between the government and the health insurance organisations. The Jordanians may also acquire health insurance at any health care organisation within \$200- \$600 annually (Muayed, 2018). However, health care can be expensive and in the absence of insurance cover, where households with severe and immediate medical needs can be forced to spend a large fraction of their household budget on health care (Burhan, Salleh \& Burhan, 2015; Salleh et al., 2017; Salleh et al., 2018;). The health insurance is composed of $31 \%$ public, $26 \%$ military, $8.5 \%$ lined by UNRWA, $1.3 \%$ University Hospital, and 6\% private health protection (Ahmad Zamil et al., 2012). The main importance of the health sector is to provide good service in addition to its contribution to the Jordanian economy as the country is almost free of natural resources. * Corresponding author.

E-mail address: a.aburumman@ammanu.edu.jo (A. Abu-Rumman)

(C) 2021 by the authors; licensee Growing Science, Canada doi: $10.5267 /$ j.msl.2020.9.018 
For this reason, the government is considering the health and tourism sectors as the main contributors to the economy. Therefore, the services rendered through both sectors will be monitored and continuously investigated. The continuing health standards and services rendered for the convenience of the consumers act as the cornerstone for providing the best quality services (Grönroos, 2001). Currently, the facility of the competitive market in the equivalent industries has become a crucial part of the businesses by which it distinguishes the service delivery through various challenges and composition. In general, services are mainly designed according to the necessity of consumers (Saeed et al., 2013). In the health sector, patient consummation remains an important topic between both medical (health) care providers and the patients (customers), while for the third party (stakeholders) it is solely based on the financial statement. In regards to customer satisfaction, Rao and Panda (2015) suggested a direct association between perceived expectations and performance. Moreover, the increase in transaction and reduction in costs are based on the loyalty of the consumer. On the other hand, the service quality is characteristically sustained to support customer satisfaction and their loyalty towards the services or products, which lead to customers' continuous repurchase of the products and services from the choice-able organisation. In the previous years, the Ministry of Health in Jordan (MOHJ) (2018) concentrated on the percentage of foreign revenues on medical (38\%) of the restorative incomes towards the end of 2014 and in addition identified to (20\%) (Health institute portrait-Jordan geographical Health technique Observation-EMRO, n.d.) in 2017. It has been reported that the prime health care sector in Jordan covers $80 \%$ of the central population and it was expected to achieve $90 \%$ by the end of the Organisation of Health Strategy (2013-2017) (The Hashemite Kingdom of Jordan Ministry of Health Strategic Plan 2013-2017, n.d.).

However, previous literature missed the investigations and the overall standards of quality management on patient loyalty that can impact patient satisfaction and service quality in Jordanian health care organisations. This exertion is important for health-care administrators and policymakers because the paper tries to clarify the effects of five dimensions of the TQM (strategic, leadership management, human resource focus information, client focus, method management, and analysis method management) (Al-Ali \& Abu-Rumman, 2019) on the client's expectations from the private and the public hospitals in Jordan. Hence, this study presented the appearance of consumers' satisfaction and consumers' loyalty by the inspiration of services quality.

\section{Literature review}

This research involved two fundamental theories, where one supports on the relationship between TQM and client's loyalty for service establishments and the other supports the relationship between the standard of services and the consumer's satisfaction. The Malcolm Baldrige Principles for Performance Excellence have expected a significant role in completing the objectives set up for the Baldrige Award. Presently, they are approved as the standard for performance excellence in the United States and around the world (Shields \& Jennings, 2013; Calvo-Mora et al., 2015). Also, the factors are primarily based on the selection of interrelated talent centre and high-performing corporation. Furthermore, they offer the establishment of an implication coordinating the necessary business conditions as a result of the formation to create a reason for action and feedback (Dang et al., 2013).

\subsection{Total Quality Management (TQM)}

SERVQUAL dimensions have been mainly used for developing the appearance of the equipment, physical facilities, communication, and personal materials. Gohain, Thambiah, \& Hong, (2018) argued that SERVQUAL lacked investigation in many hospitals across the developing countries. The investigation serves as a preparation of bringing together the objectives in order to supply the modest products and services matching the consumer's desires and expectations (Sadikoglu and Olcay, 2014). Significantly, TQM is able to control the consumer's satisfaction from two dimensions of the provided service quality, which are the technical excellence and operative quality (Saeed et al., 2013; AbuRumman, 2018). This practice of service quality dimension was referred to measure the gap or SERVQUAL scale (Ahmad Zamil et al., 2012). According to Alrabeah et al. (2015), TQM is an inevitability for the company's continuity and survival as it is compulsory to strengthen its improvement and position. The province of health care and servicescape define any specific health care facility by mentioning the tangibles apprehended through the senses of smell, sight, taste, touch, and sound (Koteswara Rao \& Kumar Panda, 2015). In this logic, the importance of bidding the TQM philosophy is to recover profitableness and increase the competitive situation in the market to boost the share price and decrease the prices of production, development, and maintenance.

\subsection{Customer Satisfaction (CS)}

CS is an essential subject for each medical (health) care suppliers, the patients (customers) themselves and different third-party stakeholders within the medical care business (Ofili, 2014). A majority of them accept client's satisfaction as a specific circumstance for the analysis of consideration based on the client's assumptions which represent the level of consumer's satisfaction. Satisfaction is a condition that happens due to the buyer's association with the suggestion over an approximate stretch of the time (Al-Abri \& Al-Balushi, 2014). Therefore, Kano's model of client's approval consideration was chosen for this study where this model includes a consumer's conduct (Jandavath \& Byram, 2016). The model encompasses three segments namely fulfilment, dissatisfaction and delight (Shields \& Jennings, 2013). 


\subsection{Customer's Loyalty (CL)}

Loyalty is established over a history of time from an identical record of consultation and sometimes even outstanding client's expectations. Bove \& Johnson (2006) proposition is one such definition of the client's loyalty. The estimation of loyalty in this study includes the degree to which a client can explore repurchasing behaviour from a service where the client would possess a constructive attitudinal nature towards the provider and reflects on the exploitation with this provider when a requirement of the service exists (The Kheng, Mahamad, Ramayah, \& Mosahab, 2010). Aliman Wan \& Nor Mohamad, (2016) argued that the health care service quality has a positive relationship with consumer's satisfaction and the expansion of consumer's loyalty. CS leads to the growth of CL, whereby the patients select to seek communication or treatment at the same non-public provider.

\section{The Theoretical Framework}

Based on the past experimental literature review, a research framework is established to investigate the relationships between TQM practices, consumer's satisfaction, and consumer's loyalty, as displayed below in Fig. 1.

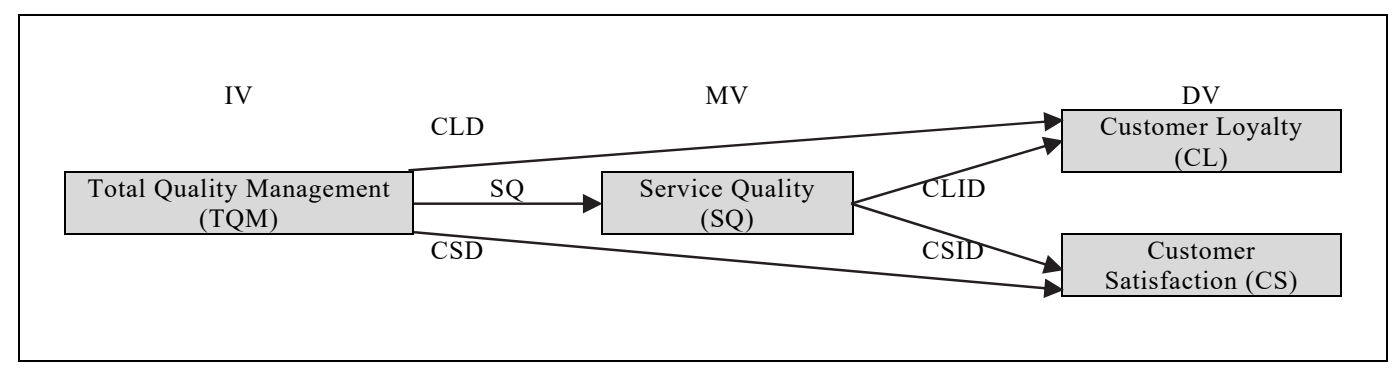

Fig. 1. Theoretical Framework. Adopted from Hair et al. (2010) and Brown (1996)

Fig. 1 displays the potential framework that determines all important factors in the relationship between the independent variable (IV), the mediator variable (MV), and the dependent variable (DV). IV contains TQM; MV contains Service Quality (SQ), and DV contains Customer Loyalty (CL) and Customer Satisfaction (CS). There is a direct (ID) and indirect (ID) effect between IV and DV, as shown in Figure 1. The D is represented by (TQM $\rightarrow$ CLD) and (TQM $\rightarrow$ CSD). The ID is represented by (TQM $\rightarrow$ SQ $\rightarrow$ CLID) and (TQM $\rightarrow$ SQ $\rightarrow$ CSID). According to Brown (1996), the examination of the indirect pathways includes the total indirect effect, which comprises of all tracks from one variable to another that is mediated by at least one other variable. The indirect pathways can be confirmed as a full mediator by comparing the indirect and direct effects. Thus, Figure 1 explains the example of the mediating effect, where the mediating effect can only take place when there are three variables namely the independent variable (TQM), the dependent variables (CL and CS), and mediating variable (SQ). The mediating variable is needed only if the direct effect between the TQM and both of CL and CS or, (CLD and CSD) is less significant than the indirect effect between SQ and both of CL and CS or, (CLID and CSID). To the contrary, if the indirect effect is less than that of the direct effect, it is not considered as a mediator.

\section{Hypothesis Development of the Study}

\subsection{Total Quality Management and Customer Loyalty}

TQM is characterised as a scheme in the process of the proposition which is supervised and integrated to focus on the association's dynamism for the continuous enhancements of all the possessions thoughts and exertion of the whole thing or even all the wide-ranging phases of efforts. On the other hand, there are different variables that can directly and indirectly affect the client's satisfaction in the health care services, such as the independent variables are accessed the mechanism, services quality, physician behaviour, physical skills and also the consumer's satisfaction which is the dependent variable quantity that modifies as a reason of these independent variables for the consumer's satisfaction and trust on those variables (Saeed et al., 2013). CL is characterised as the pleasant influence of consumer's emotions in terms of their knowledge from the service transpiration from an association (Kim et al., 2017). It has been exposed through experiments that the consumer's satisfaction influences their loyalty (Sadeh, 2017; Santouridis \& Trivellas, 2010; Gong \& Yi, 2017). Post et al. (2015) suggested a seat bend state of the connection by gathering the satisfaction levels to improve a consumer's possibility of responding in the same way. Among this provision, satisfaction has an effect on CL (McCall, Souers, Blond, \& Massie, 2016). The derived hypothesis is as below:

\section{$\mathrm{H}_{1}$ : CL has a significant direct effect on TQM.}

\subsection{Total Quality Management and Customer Satisfaction}

CS is often adopted as an independent variable in many studies (Lim et al., 2015). On an actual elementary level, there's an inevitability to illuminate whether or not satisfaction is provided with or without mediating the relationship between health care service quality and CS. Hence, it was hypothesised that: 
$\mathrm{H}_{2}$ : CS has a significant direct effect on TQM.

\subsection{Total Quality Management and Service Quality}

SQ is a special consequence in theoretical studies to assist a lot of establishments which offers modest service, maximises the customer's satisfaction and to stress the customer's loyalty. Hence, it is originated from customer loyalty and customer satisfaction (C. E. Kim et al., 2017; McCall et al., 2016; Sadeh, (2017). Kasiri et al. (2017) specified that applying service quality in the service administration's standards and health leads to client satisfaction. The growth in satisfaction is affected by the standards of the services in relation to rapidity amongst responsiveness, providing, responsibleness, the continuous handiness of services and alternative quality of services dimensions (Al-Abri, R., AlBalushi, 2014). The current study surveyed the relationship between the five service quality dimensions and the degree of satisfaction of the customers who experience the services standards and satisfaction with the assumption that the extent of satisfaction of the customers in the non-accredited health care sector. Hence, it was hypothesised that:

\section{$\mathrm{H}_{3}$ : The $S Q$ has a significant effect on TQM.}

\subsection{Service Quality and Customer Loyalty}

In the present day, a collective interest in the idea of loyalty in the service segment has been exposed. Buying an equivalent service or expect to pay a better price to advantage them, directs to the loyalty of the customer (AbuRumman, 2018). However, loyalty alone is insufficient to confer the existence of loyalty of the customer. There are factors which have a powerful effect on the psychological and behavioural component on the idea of loyalty for instant rapidity of service accuracy, delivery, trustworthiness and prompt response to requirements and desires. These reasons characterise the dimensions of SQ (C. E. Kim et al., 2017; McCall et al., 2016; Sadeh, 2017). The outcome from a previous study (Afthanorhan, et al., 2018) directed that there's a positive relationship between the SQ and degree of loyalty, as CL is usually one of the dependent variables in the quality of service model. A hypothesis was derived that:

\section{$\mathrm{H}_{4}: C L$ has a significant indirect effect on $S Q$.}

\subsection{Service Quality and Customer Satisfaction}

AL-Mhasnah et al. (20180 and Boshoff \& Gray (2004) investigated the effects of the application of SQ on patient satisfaction in hospitals using the SERVQUAL model. They confirmed that the quality of service dimensions affected patient satisfaction. Meanwhile Zhao et al. (2012) found that SQ's affects the CS and the continuous intention of mobile value-added services.

CS often adopts a mediating role between the SQ and the CL (Lim et al., 2015). As quantified before, many studies in the standard service settings have discovered the relationship between SQ and CL where others have stressed the relationship between CS and CL. On an actual elementary level, there's an inevitability to illuminate whether or not satisfaction mediates the relationship between health care SQ and CL. Therefore, the following hypothesis was drafted:

\section{$\mathrm{H}_{5}:$ CS has a significant indirect effect on $S Q$.}

\section{Methodology}

A proper methodology of analysis collection is essential for the practicality of research development. An applicable research design is important to determine the category of information, data, techniques of data collection, and the sampling methodology. Thus, the design of quantitative analysis was selected for this study as it supports the experiment methodically with the large sample of respondent's ideas regarding the commended phenomenon and subsequently the researcher takes a selected perspective of human behaviour (Lakshman, Sinha, Biswas, Charles, \& Arora, 2000). Initially, the investigator employed a survey to gather primary information. Sukamolson (2005) stated completely different compensation of limiting the quantitative analysis. This study designated national and international patients based on the explanations in the previous study. The national and international patients were recruited because they may offer proper information on SQ, leadership, patient's satisfaction as well as patient's loyalty. Furthermore, local and international patients in Jordan are very much intended to share their knowledge of the places they visited in Jordan. The sampling frame for this study comprises of local and foreign patients in private healthcare sectors in Jordan. The sample size contains 800 national and international patients in the central region of Jordan which enclosed the cities. This section also mentioned the population sample size and also the selected survey measurements. In the data and information analysis segment, statistical mathematics and techniques were utilised for data analysis, along with the verification tests. From a total of 38 health care institutions in the central region, the researcher selected five hospitals to collect information and data. The minimum requirement of sample size may vary depending on statistical techniques employed. The statistical techniques with minimum sample size requirements are presented in Table 1. 
Table 1

Statistical Techniques with Minimum Sample Size Requirements (Hair et al., 2006)

\begin{tabular}{ll}
\multicolumn{1}{c}{ Statistical Analysis } & \multicolumn{1}{c}{ Minimum Sample Size } \\
\hline Structural Equation & $\begin{array}{l}\text { Sample size as little as } 50 \text { offer valid results. } \\
\text { Suggested minimum sample sizes of } 100-150 \text { to make sure constant furthermost chance } \\
\text { estimation (MLE) answer. }\end{array}$ \\
Model (SEM) & $150-400$ is usually recommended. \\
\hline
\end{tabular}

A total of 160 patients were selected from each hospital making a total of 800 for 5 hospitals. The questionnaire was designed to mark the objectives, problems, and hypotheses of the subjects to measure the results of the independent variables between CS and CL. The questionnaire is divided into 5 parts, where the first part comprised of seven demographic variables encompassing instrument that used an insignificant and ordinal scale, for example, age, gender, occupation, education legal status, position, and monthly financial income. The second part estimated six qualifications of TQM namely strategic management, leadership, customer's focus, human resource focus data, analysis method management, and method management are controlled by thirty questions. The third part measured the patient's satisfaction through five questions. Part four measured the SQ with 22 questions. Finally, the fifth part measured the patient's loyalty through 5 questions. To ensure content validity, the questionnaire was translated by a method of double-back trans-formation because the study encompassed of both English and Arabic speaking patients. Primarily, the English version was translated into the Arabic language by two translators. Meanwhile, the Arabic version was retranslated into English by completely different tutorial employees. Many researchers practiced and used this five-idea mathematical scale for the data collection (e.g., Eisma, 2014; Al-Agili, 2012; Hunko, 2013, and Salleh, 2011). Similarly, variation in an international patients' culture favors more choices to responses than giving them only five mathematical scales as accessible in Table 2.

Table 2

Mathematical five-point scale

\begin{tabular}{|c|c|c|c|c|c|}
\hline Scales & Strongly Disagree & Disagree & Undecided & Agree & Strongly Agree \\
\hline Code & SDA & $\mathrm{DA}$ & UND & A & SA \\
\hline Items & 1 & 2 & 3 & 4 & 5 \\
\hline
\end{tabular}

The key advantage of this five-point scale is the ability to detect minor variances from patients. Consequently, to ensure the consistency between the variables and to avoid misunderstanding among respondents, the investigator employed a five-point Likert scales to measure each of the variables; (1) Strongly Disagree (SDA), (2) Disagree (DA), (3) Undecided (UND), (4) Agree (A), and (5) Strongly Agree (SA) (Table 2). Prior to working with the English and Arabic version of the questionnaires for the main survey, preliminary pre-tests were conducted to help the expansion of these questionnaires, to make sure an accurate translation of instruments and to avoid the misunderstanding or confusion. Before preferring the specific instrument to be utilised during this study, a pilot test was conducted using a suitable sample. This research framework contains dependent variables that characterise one dependent variable specifically from patient's loyalty. Data screening was done to spot data entry errors and inspect how correctly data encounters the statistical mathematics assumptions that cover the variables of descriptive statistics analysis, missing information, data and action of outlier response prejudice, homoscedasticity, normality, multiple regression, and the reliability. The complex reliability was calculated using the equation below (Hair et al. 2013, 2017):

Complex reliability $=\frac{(\Sigma s t d)^{2}}{(\Sigma s t d)^{2}+\sum \varepsilon_{j}}$

For the objective of data investigation and hypotheses testing, many statistical methods and tools are incorporated into SPSS software (version 19). Finally, the third stage is analyzing data by the Structural Equation Modelling (SEM) AMOS twenty software that conjointly contains hypothesis validity. This study is designed to test the seven hypotheses through direct and two hypotheses through indirect pathways by the mediating result. Out of total 45 respondents, $256(56.9 \%)$ of the respondents were females, and $194(43.1 \%)$ were males. The majority of the sample recorded were females, while the majority of the respondent's aged less than 25 years old (44.4\%). Similar to the previous studies, majority of the respondents were single individuals comprising of $54.4 \%$ followed by $40.2 \%$ of married patients and a minority of $5.3 \%$ of divorced individuals (McDougall \& Levesque, 2000; Martin Consuegra et al., 2007; Lee et al., 2007). Moreover, the income for respondents was estimated at approximately $37.6 \%$ for those who earned sufficiently less than $1000 \mathrm{JD}$ monthly. $\mathrm{N}$ regards to the consumer's profession, a majority of respondents $(54.0 \%)$ are the employees of the private sector, with $38 \%$ of the respondents are public servants $(38.0 \%)$. Finally, most of the respondents are Bachelor's degree $(38.9 \%)$ holders, and the lowest is from excessive-high school at $30.7 \%$. Finally, the highest group of intercontinental patients are Jordanian (27.1\%) while Syrians are the least (9.3\%). Table 4 exemplifies the correlation coefficients of the concepts that were used in this study. The correlation coefficient for the entire hidden variables was below the threshold of 0.80 . For instance, every management and HR facts were viewed with the lowest correlation coefficient of 0.21 ( $\mathrm{p}=0.000$ and significant level of 0.01 ), while the larger correlation coefficient was recorded between SQ and CL, which has been verified with a correlation coefficient of 0.85 ( $p=0.000$ with a significant degree of 0.01 ). The correlations above 0.50 are considered as strong correlations, and they were detected for TQM-CLD 
(0.75), TQM-CSD (085), TQM-SQ (0.69), and SQ-CSID (0.56). However, any correlations below 0.0 were referred to as weak correlation.

\section{Findings}

This section reviews the outcome of the data analysis installation through SPSS discussing the response value, descriptive statistic, the profile of the respondents, and screenings of data composed of linearity and homoscedasticity, correlations, reliability, and validity. The descriptive evaluation was performed by consequent tiers of fixing validity and reliability methods to verify the major score and standard deviation for the hypotheses. In the practice of directing the key study, 800 questionnaires were distributed between the local and international patients. However, of the 800, 200 were not delivered, while 150 questionnaires were incomplete (misplaced responses). The investigator found that the attention of responding rate over incredible exertion, hard effort, and extra financial charges. Therefore, a total of 450 responses were serviceable for successive analysis, giving a response percentage of $56 \%$ (Fig. 2). The sample size seemed to be enough and response rate gained was equivalent to utilize the numerous studies in the similar part, such as 70\% (Karami, 2006; 34\% (Kemperman, 2009) and so on. Figure 3 offers a direct on the response rates.

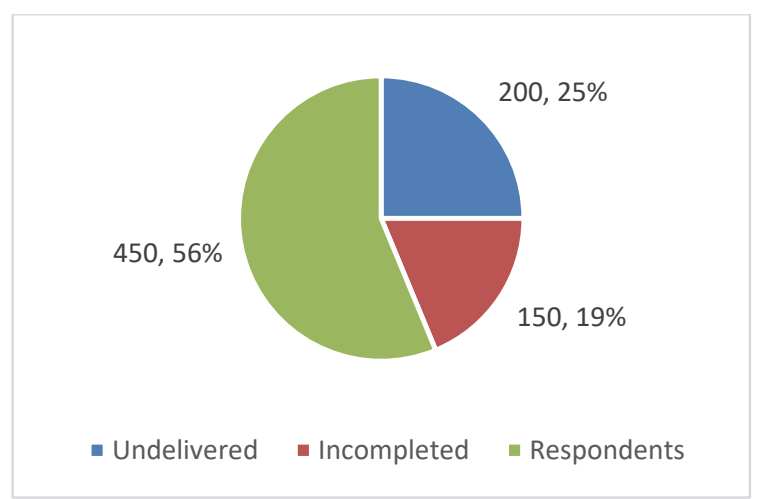

Fig. 2. Summary of Response Rates

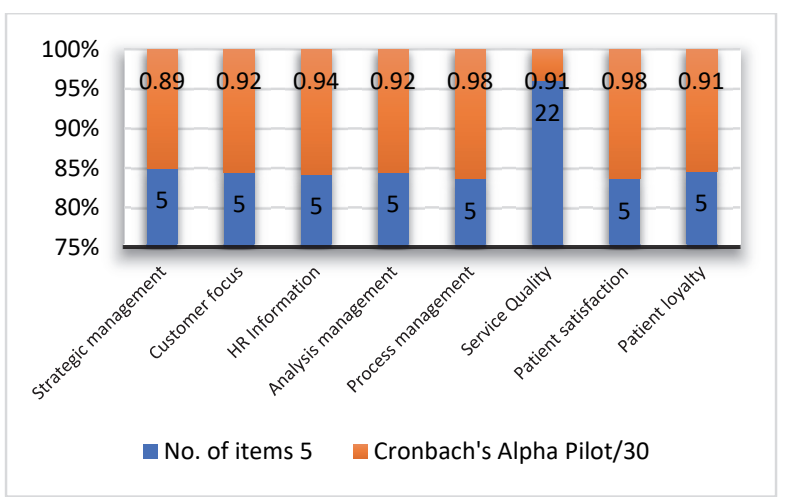

Fig. 3. The results of the pilot study

In this esteem, the investigator has piloted the best finding of the questionnaires, and it is quantified a pattern of location and intercontinental patients with 30 respondents which are carried out in Jordan. Then, the questionnaires are patterned and reviewed with the support of the researcher for any insufficiency that moreover has appeared while the respondent re-ply for these objects. following the review, the records were analyzed using SPSS for the reliability test. Fig. 3 below shows the reliability coefficient (Cronbach's alpha) for more than one implementation in the pilot study. As exposed by Fig. 3, all concepts displayed Cronbach's alpha interpretations of satisfactory values of more than 0.60 (Hair et al., 2011). A reliability value for each concept's variety ranged from 0.89 to 0.98 . The values designated that the overall concepts were of acceptable constancy. Therefore, the ultimate definite distribution is directed without any alteration. Based on Fig. 4, 450 reliable illustrations of mean and standard deviation for each variable were analyzed. The five-point intermission scales were considered into equal-sized groups of the lowest, medium, and the highest. The mean rankings that are lesser than three were categorized as low value, medium rankings of three were regarded as the mean value, while mean results greater than four were regarded as high value (Isa, 2007). As mentioned earlier, approach administration is represented using five items. As depicted in Figure 4 , the mean rankings scored average (3.82), while the mean variables were at a reasonable state (3.0 and above) without crucial consumer point (2.94). The excessive, mean scores suggested that respondents agreed with the variables for CS and CL amongst Jordanian patients in private healthcare sectors.

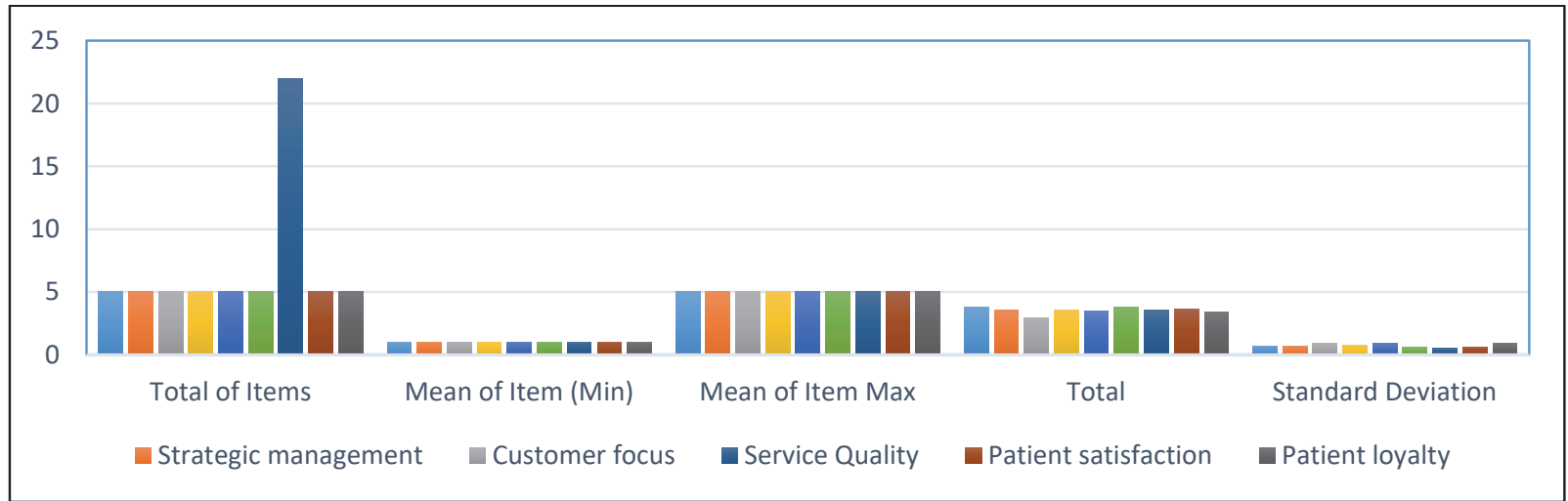

Fig. 4. Descriptive statistic of all principle constructs $(N=450)$ 
Overall, the results suggested that the CS is exceptional with a mean of 3.64 indicating a greater contribution of the respondents to CS. Likewise, the mean for CL measured 3.38. The standard deviation for all the variables for reduction ranged between 0.547 and 0.913 , which replicate the reality of appropriate variability from the internal record's customary. Fig. 4 also exposed that SQ estimated the lowest standard deviation (0.547), which may be attributable to numerous reasons: (1) respondents have no longer comprehended the statements involving quality of services in the questionnaires, (2) respondents have not agreed with the individual SQ for CL, and (3) respondents might also have similar opinions or observations of the effect of SQ on CL. On the other hand, sample traits embodied seven essential objects in this study namely; (1) gender, (2) age, (3) marital status, (4) income, (5), occupation, (6) education, and (7) nationality. The significance of each of the variables was recorded following the analyses of the demographic variables. The frequency and percentage for each individual variable are recorded based on the survey instructions in Fig. 5.

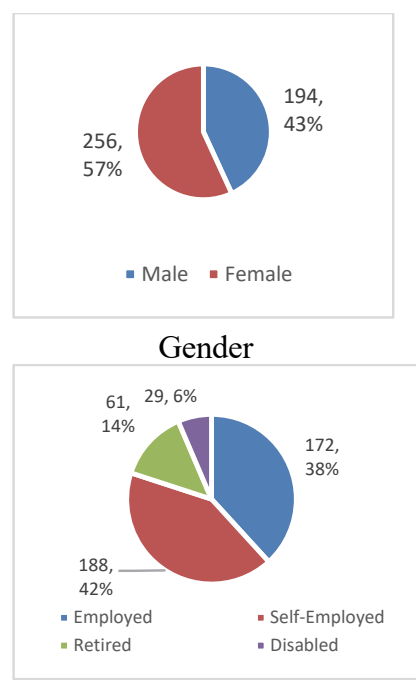

Occupation

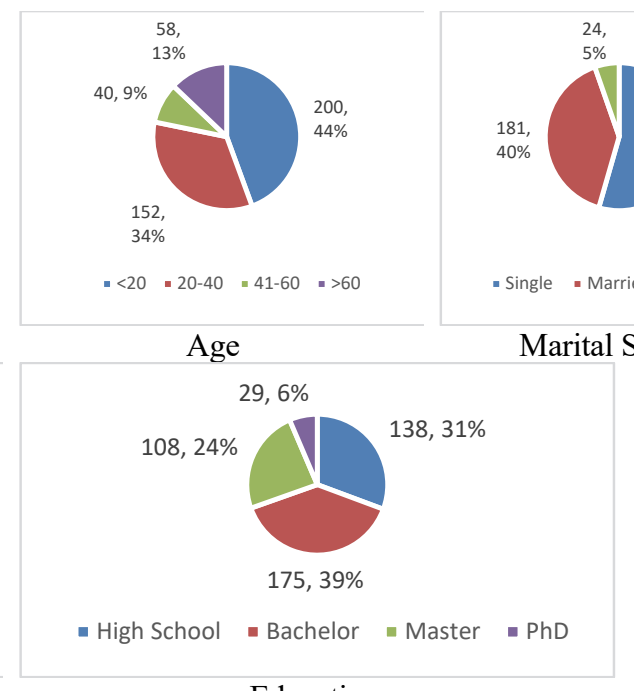

Education

Fig. 5. Personal characteristics of the participants

Table 3

Correlations for independent variables and dependent variables

\begin{tabular}{ccccccc}
\hline & TQM & CLD & CSD & SQ & CLID \\
\hline TQM & 1 & & & & \\
CLD & 0.75 & 1 & 1 & & \\
CSD & 0.85 & 0.39 & 0.38 & 1 & \\
SQ & 0.69 & 0.36 & 0.24 & 0.33 & \\
CLID & 0.21 & 0.23 & 0.34 & 0.56 & 1 \\
CSID & 0.32 & 0.32 & & 0.21 \\
\hline
\end{tabular}

Table 4 summarises the reliability coefficients of all measurements as recommended by Nunnally (1978). The complex reliability is based on the standard influences where the structural model demonstration for each concept generate a satisfactory value of above 0.60 (Nunnally, 1970). Compound reliability, on the other hand, indicates reliability and satisfaction of the dimensions of each experimental variable of more than 0.80 .

Table 4

Composite reliability of IV, DV, and MV variables

\begin{tabular}{|c|c|c|c|c|}
\hline Observed Variables & Std Loading & Std Loading $^{2}$ & Std Error (S.E) & Composite Reliability \\
\hline TQM01 & 0.33 & \multirow{4}{*}{6.7} & 0.31 & \multirow{4}{*}{0.80} \\
\hline TQM02 & 0.89 & & 0.32 & \\
\hline TQM03 & 0.99 & & 0.35 & \\
\hline TQM04 & 0.46 & & 0.36 & \\
\hline TQM (Total) & 2.67 & & 1.34 & \\
\hline CL01 & 0.88 & \multirow{4}{*}{12.1} & 0.04 & \multirow{4}{*}{0.87} \\
\hline CL02 & 0.99 & & 0.04 & \\
\hline CL04 & 0.78 & & 0.03 & \\
\hline CL05 & 0.83 & & 0.04 & \\
\hline CLD (Total) & 3.48 & & 0.15 & \\
\hline CSD01 & 0.71 & \multirow{4}{*}{6.9} & 0.07 & \multirow{4}{*}{0.96} \\
\hline CSD02 & 0.86 & & 0.08 & \\
\hline CSD03 & 0.61 & & 0.08 & \\
\hline CSD04 & 0.34 & & 0.09 & \\
\hline
\end{tabular}


Table 4

Composite reliability of IV, DV, and MV variables (Continued)

\begin{tabular}{|c|c|c|c|c|}
\hline CSD (Total) & 2.52 & & 0.32 & \multirow{9}{*}{0.99} \\
\hline SQ13 & 0.85 & \multirow{8}{*}{40.6} & 0.03 & \\
\hline SQ14 & 0.94 & & 0.03 & \\
\hline SQ15 & 0.92 & & 0.03 & \\
\hline SQ16 & 0.96 & & 0.02 & \\
\hline SQ18 & 0.48 & & 0.04 & \\
\hline SQ19 & 0.45 & & 0.05 & \\
\hline SQ21 & 0.86 & & 0.03 & \\
\hline SQ22 & 0.91 & & 0.04 & \\
\hline SQ (Total) & 6.37 & & 0.27 & \\
\hline CLID01 & 0.77 & \multirow{4}{*}{9.7} & 0.07 & \multirow{4}{*}{0.96} \\
\hline CLID02 & 0.81 & & 0.08 & \\
\hline CLID04 & 0.88 & & 0.07 & \\
\hline CLID05 & 0.65 & & 0.07 & \\
\hline CLID (Total) & 3.11 & & 0.29 & \\
\hline CSID01 & 0.33 & \multirow{4}{*}{6.7} & 0.31 & \multirow{4}{*}{0.80} \\
\hline CSID02 & 0.89 & & 0.32 & \\
\hline CSID03 & 0.99 & & 0.35 & \\
\hline CSID04 & 0.46 & & 0.36 & \\
\hline CSID (Total) & 2.67 & & 1.34 & \\
\hline
\end{tabular}

Hypothesized Model (SC) AMOS 20.0 Graphics was used to run the structural model and to check the hypothesised relationship of concepts. The results for the investigation for the goodness of healthy direction (GOD) are listed in Table 5. This assumption is exposed to be changed by the figures in the prior sector.

Table 5

Measure of fits

\begin{tabular}{|c|c|c|}
\hline Fitness Measure & Expected Values & $\begin{array}{l}\text { Current } \\
\text { Values }\end{array}$ \\
\hline CMIN & $\begin{array}{l}\text { The chi-square statistic is an overall measure of how many of the implied moments and sample moments } \\
\text { differ. The more the implied and sample moments differ, the bigger the chi-square statistic, and the } \\
\text { stronger the evidence against the null hypothesis. }\end{array}$ & 0.957 \\
\hline CMIN/DF ( $\chi 2 / d f)$ & $\begin{array}{l}\text { A value close to } 1 \text { and not exceeding three indicates a good fit. } \\
\text { A value of less than } 1 \text { indicates an over-fit of the model. }\end{array}$ & 6.686 \\
\hline CFI & $\begin{array}{l}\text { CFI value is between } 0 \text { and } 1 \text {. } \\
\text { A value close to } 1 \text { indicates a very good fit. }\end{array}$ & 0.539 \\
\hline TLI & $\begin{array}{l}\text { TLI value lies between } 0 \text { and one but is not limited to this range. } \\
\text { A value close to } 1 \text { indicates a very good fit. } \\
\text { A value greater than } 1 \text { indicates an over-fit of the model. }\end{array}$ & 0.517 \\
\hline NFI & $\begin{array}{l}\text { NFI value lies between } 0 \text { and } 1 . \\
\text { A value close to } 1 \text { indicates a very good fit. }\end{array}$ & 0.501 \\
\hline GFI & $\begin{array}{l}\text { GFI value is always less than or equal to } 1 \text {. } \\
\text { A value close to } 1 \text { indicates a perfect fit. }\end{array}$ & 0.447 \\
\hline AGFI & $\begin{array}{l}\text { AGFI value is bounded above by } 1 \text { and is not bounded by } 0 \text {. } \\
\text { A value close to } 1 \text { indicates a perfect fit }\end{array}$ & 0401 \\
\hline RMSEA & $\begin{array}{l}\text { A value of about } 0.05 \text { or less indicates a close fit of the model. } \\
\text { A value of } 0.0 \text { indicates the exact fit of the model. } \\
\text { A value of less } 0.08 \text { indicates a reasonable error of approximation. } \\
\text { The value should not be greater than } 0.1 \text {. }\end{array}$ & 0.113 \\
\hline
\end{tabular}

The remaining modified numeral in Table 5 produced a $\chi^{2}$ (chi-square) of 12048.658 , degree of freedom $=1802$ and $p$-value $=0$ which is no longer substantial at the stage of 0.050 . These values postulatte that the model fits the information appropriately excluding for the $p$-value. Although the chi-square statistic is very sensitive for the sample measurement, it is more elegant than appearing other fitting measurements. The following fitness parameters (Indices) were estimated; Chi-Square Statistics Min (CMIN), Minimum Discrepancy divided by degree of freedom (CMIN/DF), Root Mean Square Error of Approximation (RMSEA), Tucker-Lewis Index (TLI), Comparative Fit Index (CFI), Normal Fit Index (NFI), Goodness of Fit Index (GFI), and Adjusted Goodness of Fitness (AGFI). Maximum directories design did not accomplish the instruction values (Hair et al., 2010). In contrast, the findings of this research pointed out that CS is not a mediated effect. It is because most of the direct effects of constructs have more indirect effects. For example, the mediating effect of CS in the relationship between TLD and CL as illustrated in Table 6, clearly indicated that the direct effect $(0.238)$ is more than the indirect effect (0.02). This result confirms that CS is not mediated by TSP and CL.

Table 6

Mediating and non-mediating effects

\begin{tabular}{llllll}
\hline Hypothesis & Variables & & & Effect & Mediating \\
\cline { 2 - 5 } & From & To & Direct & Indirect & Not Mediating \\
\hline H1 & TQM & CL & .238 & .02 & Mediating \\
H2 & TQM & CS & $\mathbf{. 0 0 6}$ & .008 & Not Mediating \\
H4 & TQM & SQ & .315 & .036 & Mediating \\
H5 & SQ & CL & $\mathbf{. 0 3 6}$ & $\mathbf{. 0 6 0}$ & Not Mediating \\
\hline
\end{tabular}




\section{Conclusion}

The study was performed on public, governmental, and military hospitals in very crowded regions such as the capital Amman. The study examined the direct and indirect (mediating) relationships between the independent, mediating, and dependent variables. Based on the results, a direct relationship was evident between the TQM and both CL and CS, while the indirect relationship was present between SQ and both CL and CS. The investigations were also tested for normality, linearity and variance, where the expectations were met to a large extent. In contrast, the findings postulated that CL and CS are not mediated, indicating that the indirect relationship is not recommended in testing the TQM. Thus, the variables were calculated in this study to perceive and observe the SQ in public and private healthcare sectors on CL in Jordan. The greatest significant finding exposed through this research is the strong correlation between TQM, loyalty and satisfaction. Finally, all five hypotheses significantly asserted the relationship between independent, mediating, and dependent variables.

\section{References}

Abu-Rumman, A. (2018). Gaining competitive advantage through intellectual capital and knowledge management: an exploration of inhibitors and enablers in Jordanian Universities. Problems and Perspectives in Management, 16(3), 259-268.

Abu-rumman, A. (2018). TQM and Competitive Advantage: Experiences within the Engineering, Electronics, and IT Industrial Sectors in Amman. In Excellence in Services 21th International Conference, 0-12.

Ahmad Zamil, A. M., Areiqat, A. Y., \& Tailakh, W. (2012). The impact of health service quality on patients' satisfaction over private and public hospitals in Jordan: A Comparative Study. International Journal of Marketing Studies, 4(1).

Al-Abri, R., Al-Balushi, A. (2014). Patient satisfaction survey as a tool towards quality improvement. Oman Medical Journal, $29(1), 3-7$.

Al-Abbadi, L.H.M., Almomani, R.Z.Q., Rumman, A.R.A.A.A., Abu-Rumman, A. \& Khraisat, A.M.I. (2019). Impact of Human Capital Development and Human Capital Isolation Mechanisms on Innovative Performance: Evidence from Industrial Companies in Jordan. European Journal of Business and Management, 11(15), 200-209.

Aliman, N. K., \& Mohamad, Wan. Nor. (2016). Linking service quality, patients' satisfaction, and behavioral intentions: An investigation on private healthcare in Malaysia. Procedia - Social and Behavioral Sciences, 224, 141-148.

Al-Ali, A. H. and Abu-Rumman, A. (2019). The role of total quality management in the face of challenges: A study in Lafarge-Jordan. Academy of Strategic Management Journal, 18, 1-16.

Bove, L. L., \& Johnson, L. W. (2006). Customer loyalty to one service worker: Should it be discouraged? International Journal of Research in Marketing, 23(1), 79-91.

AL-Mhasnah, A., Salleh, F., Afthanorhan, A., \& Ghazali, P. (2018). The relationship between services quality and customer satisfaction among Jordanian healthcare sector. Management Science Letters, 8(12), 1413-1420.

Afthanorhan, A., Awang, Z., Salleh, F., Ghazali, P., \& Rashid, N. (2018). The effect of product quality, medical price and staff skills on patient loyalty via cultural impact in medical tourism. Management Science Letters, 8(12), 1421-1424.

Burhan, N.A.S., Salleh, F., \& Burhan, N.M.G. (2015). National intelligence and private health expenditure: Do high IQ societies spend more on health insurance? Intelligence, 52, 1-8.

Brown (1996). Effects of Trait Competitiveness and perceived intraorganizational competition on salesperson goal setting and performance. Journal of Marketing, 62(4), 88-98.

Boshoff. C \& Gray. B (2004). The relationship between service quality, customer satisfaction and buying intentions in the private hospital industry. South African Journal of Business Management, 35(4), 27-37

Calvo-Mora, A., Picón-Berjoyo, A., Ruiz-Moreno, C., \& Cauzo-Bottala, L. (2014). Contextual and mediation analysis between TQM critical factors and organisational results in the EFQM Excellence Model framework. International Journal of Production Research, 53(7), 2186-2201.

Dang, B. N., Westbrook, R. A., Black, W. C., Rodriguez-Barradas, M. C., \& Giordano, T. P. (2013). Examining the Link between Patient Satisfaction and Adherence to HIV Care: A Structural Equation Model. PLoS ONE, 8(1).

Eisma, M. (2014). Development and psychometric evaluation of the Utrecht Grief Rumination Scale. Journal of Psychopathology and Behavioral Assessment in March 2014.

El-Tohamy, A. E.-M. A., Raoush, A. T. Al, Albejaidi, F., Al-Shdaifat, E. A., Management, T. Q., Standards, U. A., ... Sallis, E. (2015). Total Quality Management. International Journal of Business and Social Research, 2(2), 51-56.

Gohain, K., Thambiah, S., \& Hong, T. C. (2018). Patients loyalty framework towards healthcare services in Malaysia. International Journal of Business and Management, 13(9), 148.

Gong, T., \& Yi, Y. (2018). The effect of service quality on customer satisfaction, loyalty, and happiness in five Asian countries. Psychology \& Marketing, 35(6), 427-442.

Grönroos, C. (2001). The perceived service quality concept - a mistake? Managing Service Quality: An International Journal, 11(3), 150152.

Hair, J. F., Hult, G. T. M., Ringle, C. M., Sarstedt, M., \& Tiele, K. O. (2017). Mirror, mirror on the wall: A comparative evaluation of composite-based structural equation modeling methods. Journal of the Academy of Marketing Science, 45, 616-632.

Hair, J.F., Black, W.C., Babin, B.J., Anderson, R.E. (2010). Multivariate Data Analysis, seventh ed. Prentice Hall, Englewood Cliffs

Hair, J. F., Black, W. C., Babin, B. J., Anderson, R. E., \& Tatham, R. L. (2006). Análise multivariada de dados. Bookman Editora.

Health Systems Profile-Jordan Regional Health Systems Observatory-EMRO. (n.d.).

He, Y., Li, W., \& Keung Lai, K. (2011). Service climate, employee commitment, and customer satisfaction. International Journal of Contemporary Hospitality Management, 23(5), 592-607.

Hunko, N (2013). The use of partial least squares path modeling in international marketing. Advances in International Marketing, 20, $277-$ 320.

Isa, F. M. (2007). Change management Initiatives and Change success in direct selling Industry: The moderating Effect of Attitude towards Change. Unpublished PHD Thesis. University Science Malaysia.

Izogo, E. E. (2015). Service quality , customer satisfaction and loyalty in automobile repair services sector. International Journal of Quality \& Reliability Management Article information (March). 
Jandavath, R. K. N., \& Byram, A. (2016). Healthcare service quality effect on patient satisfaction and behavioural intentions in corporate hospitals in India. International Journal of Pharmaceutical and Healthcare Marketing, 10(1), 48-74.

Karami, M. (2006). Actors are influencing Adoption of online Ticketing. Master thesis, Lulea University of Technology.

Kasiri, L. A., Guan Cheng, K. T., Sambasivan, M., \& Sidin, S. M. (2017). Integration of standardization and customization: Impact on service quality, customer satisfaction, and loyalty. Journal of Retailing and Consumer Services, 35, 91-97.

Kemperman, A. D. A. M., Borgers, A. W. J. \& Timmermans, H. J. P. ( 2009). Tourist shopping behavior in a historic downtown area. Tourism Management, 30, 208-218.

Kim, C. E., Shin, J.-S., Lee, J., Lee, Y. J., Kim, M., Choi, A., ... Ha, I.-H. (2017). Quality of medical service, patient satisfaction, and loyalty with a focus on interpersonal-based medical service encounters and treatment effectiveness: a cross-sectional multicenter study of complementary and alternative medicine (CAM) hospitals. BMC Complementary and Alternative Medicine, 17(1), 174.

Koteswara Rao, R., \& Kumar Panda, R. (2015). Customer perceived service quality, satisfaction, and loyalty in Indian private healthcare. International Journal of Health Care Quality Assurance, 28(July), 452-467.

Lakshman, M., Sinha, L., Biswas, M., Charles, M., \& Arora, N. K. (2000). Quantitative Vs qualitative research methods. The Indian Journal of Pediatrics, 67(5), 369-377.

Lee, C., Yoon, Y., \& Lee, S. (2007). Investigating the relationships among perceived value, satisfaction, and recommendations: The case of the Korean DMZ. Tourism Management, 28(204-214).

Lim, J. S., Hwang, Y., Kim, S., \& Biocca, F. A. (2015). How social media engagement leads to sports channel loyalty: Mediating roles of social presence and channel commitment. Computers in Human Behavior, 46, 158-167.

Martin-Consuegra, D., Molina, A., \& Esteban, A. (2007). An integrated model of price, satisfaction, and loyalty: an empirical analysis in the service sector. Journal of Product and Brand Management, 16(7), 459-468.

McCall, S. J., Souers, R. J., Blond, B., \& Massie, L. (2016). Physician satisfaction with clinical laboratory services a college of American pathologists Q-probes study of 81 institutions. Archives of Pathology and Laboratory Medicine, 140(10), 1098-1103.

McDougall, G. H. G., \& Levesque, T. (2000). Customer satisfaction with services: Putting perceived value into the equation. Journal of Service Marketing, 14(5), 392-410.

Nunnally J.C. (1978). Psychometric Theory (2 $2^{\text {nd }}$ ed.). New York: McGraw-Hill.

Post, D. M., McAlearney, A. S., Young, G. S., Krok-Schoen, J. L., Plascak, J. J., \& Paskett, E. D. (2015). Effects of Patient Navigation on Patient Satisfaction Outcomes. Journal of Cancer Education: The Official Journal of the American Association for Cancer Education, $30(4), 728-735$.

Sadeh, E. (2017). Interrelationships among quality enablers, service quality, patients' satisfaction, and loyalty in hospitals. The TQM Journal, 29(1), 101-117.

Sadikoglu, E., Sciences, H. Olcay.-A. in D., \& 2014, undefined. (n.d.). The effects of total quality management practices on performance and the reasons for and the barriers to TQM practices in Turkey. Hindawi.Com.

Saeed, R., Osama Ghafoor, M., Sarwar, B., Nawaz Lodhi, R., Muhammad Arshad, H., \& Ahmad, M.(2013). Factors Affecting Customer Satisfaction in Health Care Servicesin Pakistan. Journal of Basic Applied Science Resources, 3(5), 947-952.

Salleh, S (2011). Factors influencing destination brand loyalty in Jordan. PSU - USM International Conference on Humanities and Social Sciences 2011. "Transforming Research for Sustainable Community" 3 - 4 October 2011

Salleh, F., Mustafa, N., Daud, W. N. W., Yazid, A. S., Ghazali, P. L., Burhan, N. A. S., \& Hosnih,M. N. (2018). Micro health takaful framework for poor communities in Malaysia. International Journal of Academic Research in Business and Social Sciences, 8(11), 1294-1302.

Salleh, F., Mustafa, N., Daud, W.N.W, Remli, N., Burhan, N.A.S. (2017). A review of the importance on the need of micro medical and health takaful Proceedings of the $30^{\text {th }}$ International Business Information Management Association Conference,

IBIMA 2017 - Vision 2020: Sustainable Economic development, Innovation anagement, and Global Growth

Santouridis, I., \& Trivellas, P. (2010). Investigating the impact of service quality and customer satisfaction on customer loyalty in mobile telephony in Greece. The TQM Journal, 22(3), 330-343.

Shields, J. A., \& Jennings, J. L. (2013). Using the Malcolm Baldrige “Are We Making Progress" Survey for Organizational Self-Assessment and Performance Improvement. Journal for Healthcare Quality, 35(4), 5-15.

Sukamolson, S. (2007). Fundamentals of quantitative research.

The Hashemite Kingdom Of Jordan Ministry of Health Strategic Plan 2013-2017. (n.d.).

The Kheng, L. L., Mahamad, O., Ramayah, T., \& Mosahab, R. (2010). Study of banks in Penang, Malaysia Impact of Service Quality on Customer Loyalty: A. International Journal of Marketing Studies, 2(2).

Uche Ofili, O. (2014). Patient Satisfaction in Healthcare Delivery - a Review of Current Approaches and Methods. European Scientific Journal, 10(25), 1857-7881.

Zhao, L., Lu, Y., Zhang, L., \& Chau, P. Y. (2012). Assessing the effects of service quality and justice on customer satisfaction and the continuance intention of mobile value-added services: An empirical test of a multidimensional model. Decision Support Systems, 52(3), 645-656.

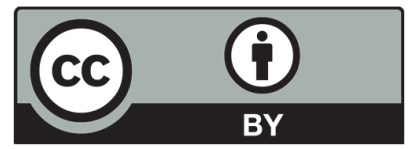

(C) 2020 by the authors; licensee Growing Science, Canada. This is an open access article distributed under the terms and conditions of the Creative Commons Attribution (CC-BY) license (http://creativecommons.org/licenses/by/4.0/). 